\title{
Delayed Brachial Plexus Palsy after Clavicular Fracture
}

\author{
Kazuto Katsuse, Satoshi Kodama, Kayako Okazaki and Tatsushi Toda
}

Key words: traumatic brachial plexopathy, medial cord, lateral cord, magnetic resonance neurography, clavicular fracture

(Intern Med 60: 2511-2512, 2021)

(DOI: 10.2169/internalmedicine.6988-20)

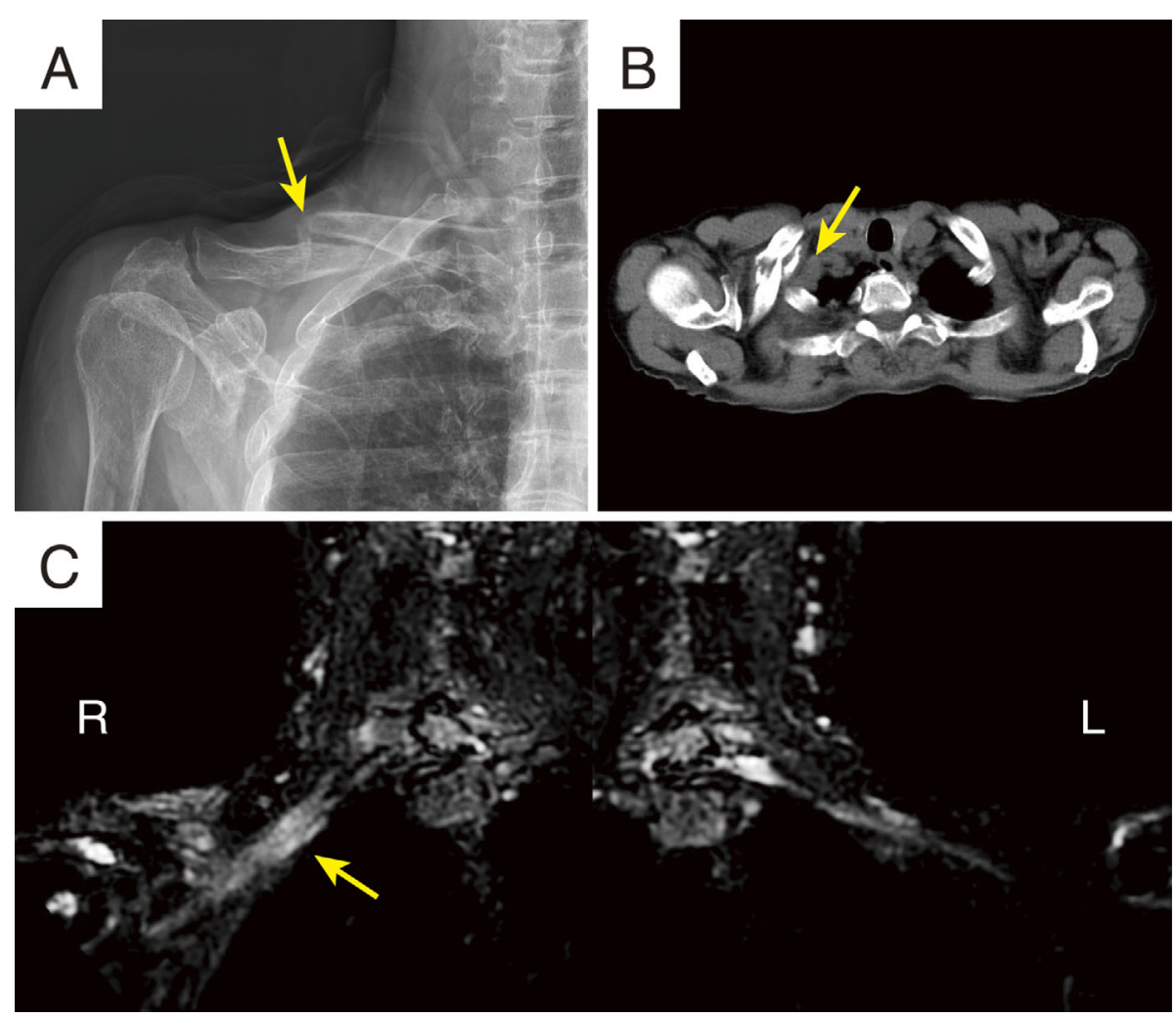

Picture.

A 65-year-old woman manifested subacute weakness of the right upper extremity and numbness of the right palm. She had suffered a displaced right clavicular midshaft fracture two weeks earlier (Picture A). A neurological examination revealed a decreased strength in the muscles innervated by the musculocutaneous, median, and ulnar nerves, whereas those supplied by the axillary and radial nerves appeared unaffected, suggesting medial and lateral cord impairment in the right brachial plexus. The area of reduced sensation of touch mostly corresponded to the distribution of the median and ulnar nerves. Chest computed tomography revealed a displaced clavicular fragment pushing the soft tissues in the subclavicular space (Picture B). Brachio-cervical magnetic resonance neurography (MRN) with short T1 inversion recovery sequences showed longitudinal right brachial plexus swelling and focal high intensity in the segment under the fracture site (Picture C); this presumably reflected neural edema due to compression by the bone fragment. Brachial plexus palsy is a rare complication following clavicular fracture and can appear at an interval of several weeks after the trauma $(1,2)$. MRN may be useful for its diagnosis.

Department of Neurology, Graduate School of Medicine, The University of Tokyo, Japan

Received: December 24, 2020; Accepted: January 5, 2021; Advance Publication by J-STAGE: February 22, 2021

Correspondence to Dr. Kazuto Katsuse, katsuse-tky@umin.ac.jp 
The authors state that they have no Conflict of Interest (COI).

\section{Acknowledgement}

We are grateful to Dr. Masayuki Ueda, Dr. Toshiyuki Kakumoto and Dr. Hiroyuki Ishiura for their helpful advice concerning this study.

\section{References}

1. Barbier $\mathrm{O}$, Malghem $\mathrm{J}$, Delaere $\mathrm{O}$, et al. Injury to the brachial plexus by a fragment of bone after fracture of the clavicle. J Bone Joint Surg Br 79: 534-536, 1997.

2. Saito T, Matusmura T, Takeshita K. Brachial plexus palsy after clavicle fracture: 3 cases. J Shoulder Elbow Surg 29: e60-e65, 2020.

The Internal Medicine is an Open Access journal distributed under the Creative Commons Attribution-NonCommercial-NoDerivatives 4.0 International License. To view the details of this license, please visit (https://creativecommons.org/licenses/ by-nc-nd/4.0/).

\footnotetext{
(C) 2021 The Japanese Society of Internal Medicine Intern Med 60: 2511-2512, 2021
} 